ARTICLE

\title{
Action potential broadening in a presynaptic channelopathy
}

\author{
Rahima Begum¹, Yamina Bakiri ${ }^{1}$, Kirill E. Volynski ${ }^{1} \&$ Dimitri M. Kullmann ${ }^{1}$
}

Brain development and interictal function are unaffected in many paroxysmal neurological channelopathies, possibly explained by homoeostatic plasticity of synaptic transmission. Episodic ataxia type 1 is caused by missense mutations of the potassium channel Kv1.1, which is abundantly expressed in the terminals of cerebellar basket cells. Presynaptic action potentials of small inhibitory terminals have not been characterized, and it is not known whether developmental plasticity compensates for the effects of Kv1.1 dysfunction. Here we use visually targeted patch-clamp recordings from basket cell terminals of mice harbouring an ataxia-associated mutation and their wild-type littermates. Presynaptic spikes are followed by a pronounced afterdepolarization, and are broadened by pharmacological blockade of Kv1.1 or by a dominant ataxia-associated mutation. Somatic recordings fail to detect such changes. Spike broadening leads to increased $\mathrm{Ca}^{2}+$ influx and GABA release, and decreased spontaneous Purkinje cell firing. We find no evidence for developmental compensation for inherited Kv1.1 dysfunction.

\footnotetext{
${ }^{1}$ UCL Institute of Neurology, University College London, Queen Square, London WC1N 3BG, UK. Correspondence and requests for materials should be addressed to D.M.K. (email: d.kullmann@ucl.ac.uk).
} 
K v1 channels are mainly expressed in axons throughout the central nervous system and play important roles in action potential initiation and repolarization ${ }^{1-3}$. Several heterozygous mutations in the KCNA1 gene, which encodes the Kv1.1 subunit, have been identified in episodic ataxia type 1 (EA1), a familial disorder characterized by paroxysmal cerebellar incoordination and interictal myokymia, and occasionally with other features such as epilepsy ${ }^{4-8}$. Consistent with the prominent features of the syndrome, Kv1.1 is most abundantly expressed in the terminals of cerebellar basket cells ${ }^{9-12}$.

Heterologous expression studies have shown that mutations disrupt channel function through a variety of changes in assembly, trafficking and kinetics, often with dominant negative effects $^{13-15}$. The consequences depend on the channel composition, as Kv1.1 co-assembles with other members of the Kv1 family and with beta subunits, and it is therefore difficult to predict the consequence of a given mutation in situ from heterologous expression studies. Indeed, some mutations may interfere with fast inactivation, offsetting other loss-of-function effects $^{16,17}$. A mouse knock-in model of EA1 (Kcnal ${ }^{\mathrm{V} 408 \mathrm{~A} /+}$ ) bypasses these limitations of heterologous expression, and exhibits impaired cerebellar coordination when stressed ${ }^{18}$. Importantly, and unlike most mouse models of human genetic disease, the disease phenotype is recapitulated in the heterozygous state $^{18}$.

How does Kv1.1 channel dysfunction affect synaptic and circuit function, leading to cerebellar incoordination? In the neocortex, Kv1 channels play a key role in action potential repolarization $^{1}$, and also determine the latency to the first action potential in fast-spiking interneurons ${ }^{2,19}$. Little is known, however, of the consequences of Kv1.1 mutations in the cerebellar cortex. A study using targeted patch-clamp recordings showed that $\alpha$-dendrotoxin $(\alpha$-DTx), a blocker of Kv1.1 and Kv1.2 channels ${ }^{20}$, attenuates $\mathrm{K}^{+}$currents in voltageclamp recordings from basket cell terminals, where both channel subunits are highly concentrated ${ }^{21}$. However, the consequences for action potential shape are unknown, and current-clamp recordings have not been reported. Although $\alpha$-DTx increased spontaneous inhibitory postsynaptic currents (IPSCs) in Purkinje cells $^{22}$, in another study it had no effect on action potentialdependent $\mathrm{Ca}^{2+}$ fluorescence transients measured from basket cell boutons ${ }^{23}$. Moreover, it is difficult to extrapolate from acute pharmacological blockade of Kv1.1 and Kv1.2 channels to constitutive dysfunction of Kv1.1 with dominant negative effects that depend on channel stoichiometry ${ }^{13-17}$. The $K_{c n a 1} \mathrm{V408A/+}$ mouse shows an increase in spontaneous IPSC frequency in Purkinje cells relative to wild-type littermates ${ }^{18}$, but how this relates to action potential-dependent GABA release from basket cell terminals is unclear. Furthermore, abundant evidence exists for developmental homoeostatic compensation for pharmacological manipulation of ion channels and receptors ${ }^{24}$. Do similar compensatory mechanisms occur in response to inherited mutations of presynaptic ion channels? To address these questions, we first characterized presynaptic action potentials at cerebellar basket cell terminals of wild-type mice, and then compared the effects of pharmacological and genetic manipulations of Kv1.1 on presynaptic spike shape, action potential $\mathrm{Ca}^{2}+$ influx, and GABAergic inhibition of Purkinje cells.

\section{Results}

Presynaptic spikes are broadened by Kv1.1 blockade. To understand the normal role of Kv1.1 in basket cells we examined the effect of the highly specific Kv1.1 blocker DTx- $\mathrm{K}^{25}$ on action potential shape. Targeted patch-clamp recordings were obtained from somata or terminals of basket cells in acute cerebellar slices from wild-type mice, bred on the same background as Kcnal $1^{\mathrm{V} 408 \mathrm{~A}}$ / mice described below ${ }^{18}$. Somatic recordings from basket cells showed no effect of $200 \mathrm{nM}$ DTx-K on action potential width (Fig. 1a,b). A likely explanation is that Kv1.1 is predominantly expressed in axons and terminals of basket cells ${ }^{9,11}$, and plays only a small role in somata. Patch-clamp recordings from basket cells have indeed detected potassium currents with biophysical and pharmacological properties consistent with Kv1.1 or Kv1.2 (refs 21,26). We therefore targeted basket cell terminals for patch-clamp recordings.

Presynaptic terminals were initially identified under infrared differential interference contrast (DIC), and had a high input resistance, little or no sag potential, and were able to spike upon 1 -ms current injection (passive membrane properties are given in Supplementary Table 1). Prolonged depolarizing current pulses failed to evoke stable trains of action potentials (see also Supplementary Fig. 1a). Instead, repeated brief pulses reliably triggered action potentials at either 55 or $100 \mathrm{~Hz}$ (see also Supplementary Fig. 1b,c), with modest progressive spike broadening. Evoked presynaptic action potentials were followed by a prominent afterdepolarization (ADP), which reversed between 50 and $-40 \mathrm{mV}$ (see also Supplementary Fig. 2a,b). Because $\mathrm{GABA}_{\mathrm{A}}$ autoreceptors are prominent in another type of cerebellar interneurons, stellate cells ${ }^{27}$, we asked whether the ADP was abolished by blocking these receptors. Bath application of picrotoxin $(\mathrm{PTx}, 100 \mu \mathrm{M})$, however, only led to a small albeit significant decrease in the area of the ADP (Supplementary Fig. 2c,d), suggesting that GABA release from basket cell terminals acting on autoreceptors plays only a small role.

In contrast to somatic action potentials, presynaptic spike width (measured at $-30 \mathrm{mV}$ ) was robustly prolonged by DTx-K (Fig. 1a,b; baseline: $0.96 \pm 0.03 \mathrm{~ms}$; DTx-K: $1.15 \pm 0.02 \mathrm{~ms}$; $P<0.001$, paired $t$-test, $n=11)$. The ADP was however unaffected. We compared the effects of DTx-K to those of charybdotoxin (ChTx), a blocker of the large conductance calcium- and voltage-activated potassium channel $\mathrm{BK}_{\mathrm{Ca}}$, which is usually abundantly expressed at presynaptic terminals in close association with the active zone ${ }^{28}$ (but see ref. 29). Unexpectedly, ChTx $(100 \mathrm{nM})$ led to spike broadening at the soma (Fig. 1c: baseline: $1.28 \pm 0.10 \mathrm{~ms}$; ChTx: $1.55 \pm 0.13 \mathrm{~ms} ; P<0.05$, paired $t$-test, $n=7$ ) but not in presynaptic boutons. Thus, two $\mathrm{K}^{+}$ channels show complementary roles in determining spike shape in basket cells.

Kv1.1 modulates presynaptic $\mathrm{Ca}^{2+}$ influx and GABA release. A previous study reported no effect of $\alpha$-DTx on action potentialevoked $\mathrm{Ca}^{2}+$ fluorescence transients measured in basket cell terminals ${ }^{23}$. We re-examined the role of Kv1.1 in presynaptic spike-evoked $\mathrm{Ca}^{2}+$ influx by patch clamping basket cell bodies in wild-type mice. Two-photon fluorescence excitation microscopy was used to image individual boutons apposed to Purkinje cell somata (Fig. 2a). Line scans were taken before and after bath perfusion of $200 \mathrm{nM}$ DTx-K (Fig. 2b,c, see Methods for detailed protocols and calibration of $\mathrm{Ca}^{2}+$ responses). To improve the signal-to-noise ratio, we took the integral of the Fluo-4 fluorescence signal for $200 \mathrm{~ms}$ from the first action potential, as a measure of total action potential-evoked $\mathrm{Ca}^{2+}$ influx $\Delta\left[\mathrm{Ca}^{2+}\right]$. A non-stationary single-compartment model $^{30}$ incorporating the $\mathrm{Ca}^{2+}$ buffer parvalbumin provided a good fit to the fluorescence transients (Fig. 2c), confirmed that the $200 \mathrm{~ms}$ integral varied linearly with $\Delta\left[\mathrm{Ca}^{2+}\right]$ (see also Supplementary Fig. 3), and further yielded an estimate of the absolute $\mathrm{Ca}^{2}+$ concentration change. 
a
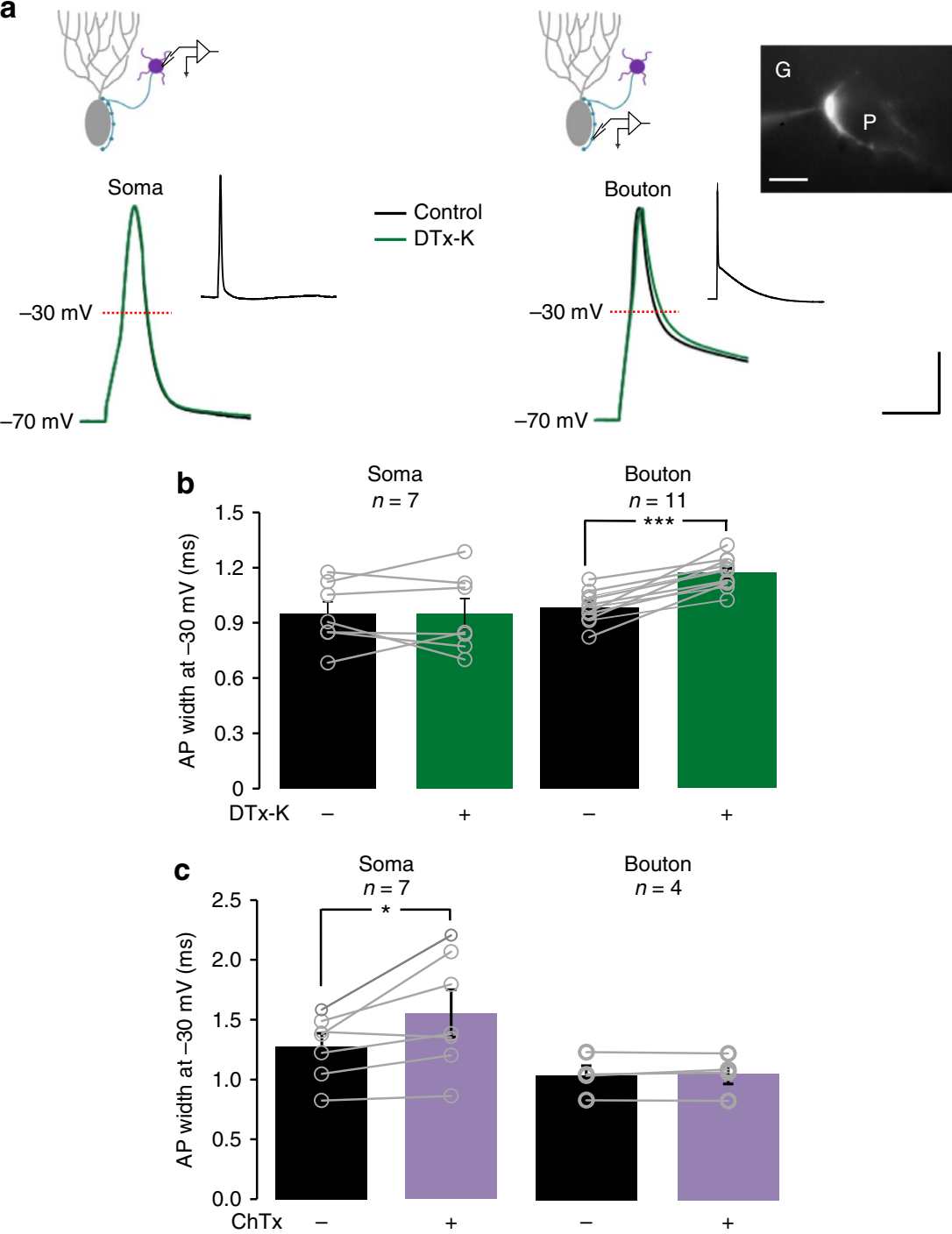

Figure 1 | Compartment-specific roles of $\mathbf{K}^{+}$channels in action potential shape in cerebellar basket cells. (a) Representative action potentials recorded from the soma (left) or bouton (right) of cerebellar basket cells, before (black trace) and after (green trace) Kv1.1 blockade with DTx-K. Top: schematics illustrating recording sites. Inset: action potentials at slow time base, showing a prominent ADP at the bouton. Scale bar, $20 \mathrm{mV} ; 2 \mathrm{~ms}$ (main traces); $40 \mathrm{mV}$ 200 ms (insets). The fluorescence image at right shows a cerebellar basket cell bouton labelled with Alexa 568. G and P indicate granule cell and Purkinje cell layer, respectively. Scale bar, $10 \mu \mathrm{m}$. (b) Summary data showing selective effect of DTx-K on presynaptic spike width measured at $-30 \mathrm{mV}$. Circles show individual experiments. (c) $\mathrm{BK}_{\mathrm{Ca}}$ blockade with $\mathrm{ChTx}$ led to somatic action potential broadening. ${ }^{\star} P<0.05$, ${ }^{\star \star *} P<0.001$; paired $t$-tests.

DTx-K perfusion led to a $21 \pm 9 \%$ increase in the normalized $\mathrm{Ca}^{2}+$ fluorescence integral $(P<0.05$, Wilcoxon signed-rank test for paired data), which was not seen in control experiments followed for the same time (Fig. 2d). Dividing the estimated total $\mathrm{Ca}^{2+}$ concentration change $\left(\Delta\left[\mathrm{Ca}^{2+}\right] \sim 10 \mu \mathrm{M}\right.$ per action potential under baseline conditions) into the approximate bouton volume (estimated from DIC or Alexa images as roughly $1 \mathrm{fL}$ ), we further estimated that $\sim 6.0 \times 10^{6} \mathrm{Ca}^{2+}$ ions (equivalent to a charge of $1.93 \mathrm{fC}$ ) enter the bouton for each action potential under baseline conditions. A six-state kinetic model of P/Q-type $\mathrm{Ca}^{2+}$ channels $^{31}$, which predominate in basket cells $s^{32}$, yields an estimate of their gating kinetics when driven by a presynaptic action potential waveform that incorporates the ADP recorded in boutons. Taking into account the single channel conductance and driving force ${ }^{30}$, we estimate that $\sim 0.04 \mathrm{fC}$ enters via each $\mathrm{Ca}^{2+}$ channel. This yields an estimate of $\sim 50 \mathrm{P} / \mathrm{Q}$-type $\mathrm{Ca}^{2+}$ channels present in a typical bouton. Although the driving force for $\mathrm{Ca}^{2+}$ entry increases following repolarization, we found that subtracting the ADP from the action potential waveform actually led to a $\sim 3 \%$ decrease in the total $\mathrm{Ca}^{2+}$ influx (Supplementary Fig. 4), consistent with accelerated deactivation. In contrast, prolonging the decay phase of the action potential led to a linear increase in $\mathrm{Ca}^{2+}$ influx over a wide range (Fig. 2e). This gives an independent estimate of the effect of spike broadening due to DTx-K, corresponding to an $18 \%$ increase in $\mathrm{Ca}^{2+}$ influx.

Two independent approaches $\left(\mathrm{Ca}^{2+}\right.$ fluorescence imaging and kinetic modelling of $\mathrm{P} / \mathrm{Q}$-type channels), thus converge on the conclusion that Kv1.1 channel blockade causes $\sim 20 \%$ more $\mathrm{Ca}^{2+}$ influx per action potential.

Previous studies using $\alpha$-DTx revealed a large increase in spontaneous IPSC amplitude and frequency in Purkinje cells $^{22,23}$. We asked how DTx-K affects evoked IPSCs by recording from Purkinje cells, while activating axons in the Purkinje cell layer. Kv1.1 blockade with DTx-K led to a $45 \pm 19 \%$ increase in pharmacologically isolated monosynaptic IPSCs $(n=15, P<0.05$, Wilcoxon matched pairs signed-rank test; Supplementary Fig. 5). This is consistent with a $\sim 20 \%$ 


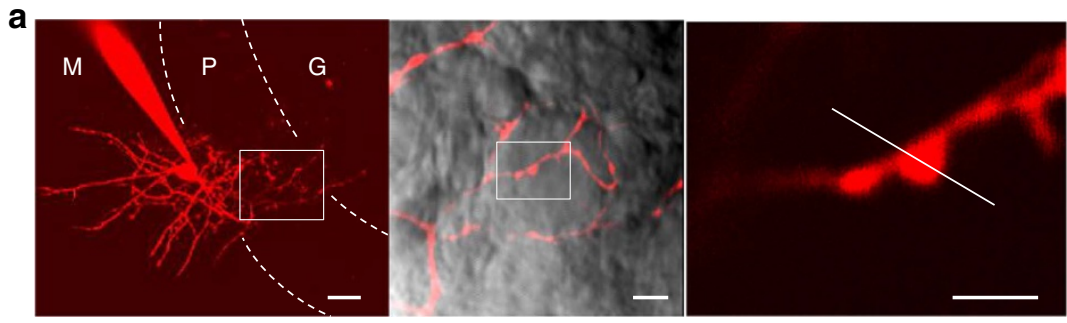

b

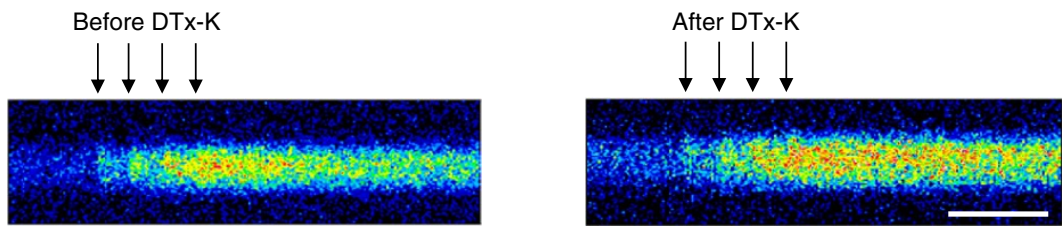

C

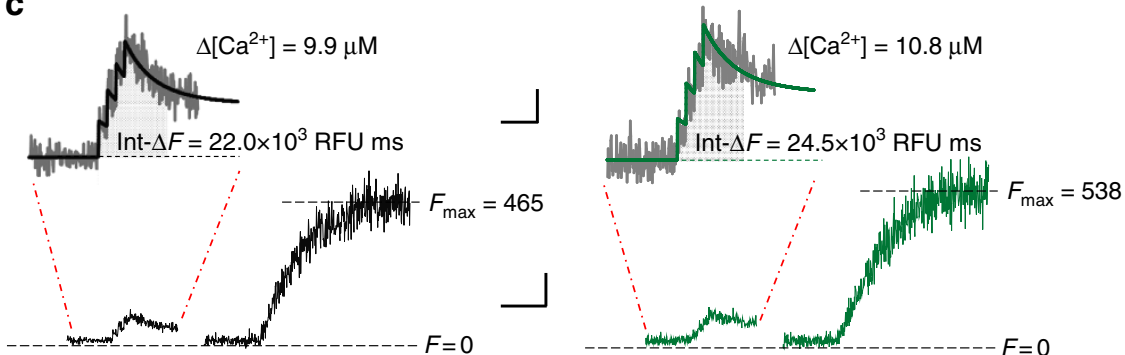

d

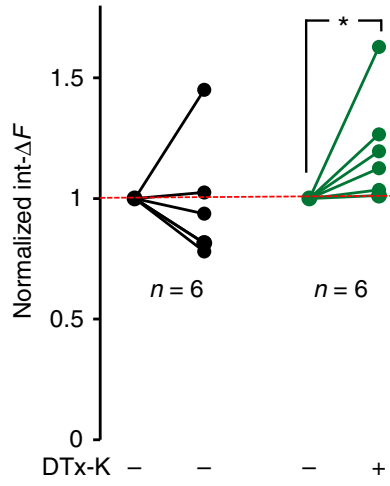

e

$$
C 0 \underset{\beta 1(V)}{\stackrel{\alpha 1(V)}{\rightleftarrows}} C 1 \underset{\beta 2(V)}{\stackrel{\alpha 2(V)}{\rightleftarrows}} C 2 \underset{\beta 3(V)}{\stackrel{\alpha 3(V)}{\rightleftarrows}} C 3 \underset{\beta 4(V)}{\stackrel{\alpha 4(V)}{\rightleftarrows}} C 4 \underset{\beta}{\stackrel{\alpha}{\rightleftarrows}} O
$$

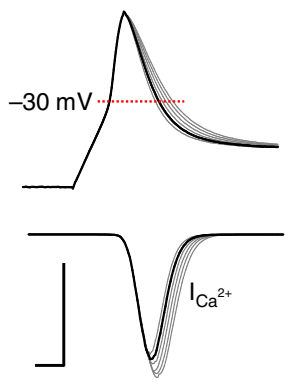

Figure 2 | Kv1.1 modulates presynaptic action potential-evoked $\mathbf{C a}^{2}+$ influx and GABA release. (a) Cerebellar basket cell filled with Alexa 594 , under multi-photon fluorescence microscopy. M, P and G indicate molecular, Purkinje cell and granule cell layers, respectively. Middle: axon superimposed on transmitted light image, showing boutons apposed to the soma of a Purkinje cell. Inset (expanded at right) shows imaged bouton and line scan position (white dashed line). Scale bar, (left) $20 \mu \mathrm{m}$; (middle) $5 \mu \mathrm{m}$; (right) $2 \mu \mathrm{m}$. (b) Representative line scans (averages of four trials), showing Fluo-4 fluorescence response to a train of four action potentials at $40 \mathrm{~Hz}$ (arrows) elicited at the soma before (left) and 10 min after DTx-K perfusion (right). Scale bar, $75 \mathrm{~ms}$. (c) Fluo-4 fluorescence time courses (same bouton as in b) elicited by four action potentials at $40 \mathrm{~Hz}$ followed by 50 action potentials at $100 \mathrm{~Hz}$ to saturate Fluo-4 (Scale bar, 200 relative fluorescence units (RFU); $200 \mathrm{~ms}$ ). Insets: zoomed responses to four action potentials (Scale bar, 50 RFU; $100 \mathrm{~ms}$ ). Black and green lines represent non-stationary single-compartment model fits before and after application of DTx-K, respectively. Model-predicted values for the total action potential-evoked $\mathrm{Ca}^{2+}$ influx $\left(\Delta\left[\mathrm{Ca}^{2+}\right]\right)$ are shown next to each trace. Shaded areas under the traces indicate the Fluo-4 fluorescence integrated over $200 \mathrm{~ms}$ from the beginning of stimulation (Int- $\Delta F$ ), which is proportional to $\Delta\left[\mathrm{Ca}^{2+}\right.$ ] (Supplementary Fig. 3). (d) Summary of the normalized effects of $\mathrm{DTx}-\mathrm{K}$ on Int- $\Delta F$, compared with control experiments where $\mathrm{DTx}-\mathrm{K}$ was not applied. ${ }^{\star} P<0.05$, Wilcoxon signed-rank test for paired data. (e) Top, gating model for P/Q-type presynaptic $\mathrm{Ca}^{2}+$ channels $^{31}$. Left, average time course of $\mathrm{Ca}^{2}+$ current through a single P/Q-type channel (10,000 simulations including failures) elicited by action potentials of different widths. Modified action potential waveforms (grey) were generated by scaling the repolarization phase of the experimental control trace (black) between 0.9 and 1.4. Right, calculated dependence of evoked $\mathrm{Ca}^{2+}$ current integral $\left(\mathrm{I}_{\mathrm{Ca}}{ }^{2+}\right)$ on action potential width measured at $-30 \mathrm{mV}$.

increase in $\mathrm{Ca}^{2}+$ influx, assuming a $\mathrm{Ca}^{2+}$ current cooperativity ( $m$ ) of $\sim 2$ (refs 33,34).

Thus, delayed repolarization secondary to Kv1.1 blockade leads to increased $\mathrm{Ca}^{2+}$ influx and enhanced neurotransmitter release. How does the acute effect of manipulating Kv1.1 channels compare to genetic disruption of Kv1.1 in EA1?
Increased spike width and GABA release in $\mathrm{Kcnal}^{\mathrm{V} 408 \mathrm{~A} /+}$ mice. We repeated action potential recordings from basket cells in Kcnal ${ }^{\mathrm{V} 408 \mathrm{~A} /+}$ mice, which harbour a missense mutation that underlies EA1 (ref. 18), and their wild-type littermates $\left(\mathrm{Kcnal}^{+/+}\right)$. Data were acquired and analysed blind to genotype. Passive membrane properties and current threshold for eliciting 
a

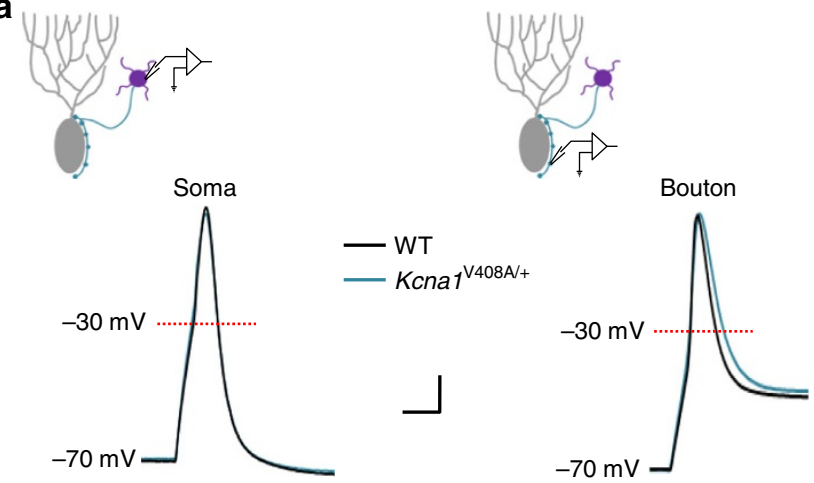

b

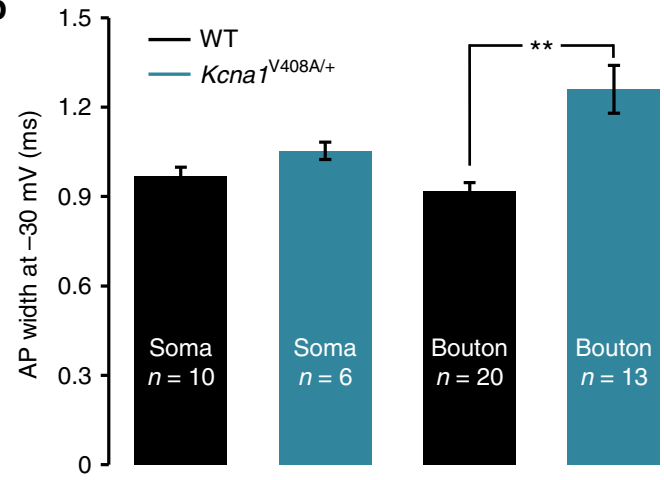

Figure 3 | Action potentials recorded in cerebellar basket cells of Kcna1 $\mathbf{V 4 0 8 A}$ / mice. (a) Superimposed representative action potentials recorded from somata (left) or boutons (right) of cerebellar basket cells from wild-type or Kcna1 ${ }^{\mathrm{4} 408 \mathrm{~A} /+}$ mice. Scale bar, $10 \mathrm{mV} ; 1 \mathrm{~ms}$.

(b) Presynaptic spike width at $-30 \mathrm{mV}$ was longer in $K \mathrm{cna}^{\mathrm{V}} \mathrm{V08 \textrm {A } / +}$ boutons. ${ }^{\star \star} P<0.01$, unpaired $t$-test.

action potentials were unaffected by the mutation (Supplementary Table 1). Recordings of somatic action potentials also failed to reveal a significant difference in action potential width between genotypes (Fig. 3a). A robust difference in duration was however observed in presynaptic boutons. Action potential width was $\sim 35 \%$ greater in Kcnal $1^{\mathrm{V} 408 \mathrm{~A} /}+$ mice $(1.26 \pm 0.08 \mathrm{~ms}, n=13)$ than in Kcna1 ${ }^{+/+}$mice $(0.93 \pm 0.03 \mathrm{~ms}$, $n=20$; unpaired $t$-test: $P<0.002$; Fig. $3 \mathrm{a}, \mathrm{b})$. Trains of action potentials elicited at 55 and $100 \mathrm{~Hz}$ showed a similar spike broadening as in wild-type mice (Supplementary Fig. 1c), showing no evidence of occlusion between the effects of repetitive spiking and genotype. DTx-K failed to broaden action potential duration recorded from the presynaptic terminals of basket cells in Kcna1 $\mathrm{V408 \textrm {A } / +}$ mice, consistent with the loss of function of Kv1.1-containing channels (Supplementary Fig. 6). We also observed no difference in the ADP between the genotypes.

The Kcnal ${ }^{\mathrm{V} 408 \mathrm{~A} /+}$ mutation thus broadens the spike at least as much as acute application of DTx-K in wild-type boutons. We observed no evidence of homoeostatic compensation by other channels correcting for loss of Kv1 channel function in the knock-in model of EA1.

Increased inhibition of Purkinje cells in $\mathrm{Kcnal}^{\mathrm{V} 408 \mathrm{~A} /+}$ mice. An increase in spontaneous GABAergic IPSCs has previously been reported in Purkinje cells of the Kcnal ${ }^{\mathrm{V} 408 \mathrm{~A} /+}$ mouse $^{18}$. It is technically difficult to compare presynaptic $\mathrm{Ca}^{2+}$ influx between genotypes, and the amplitudes of evoked IPSCs are uninformative when evoked by extracellular stimulation of multiple axons. Instead, we compared the paired-pulse ratio of
IPSCs recorded in Purkinje cells as a surrogate measure of action potential-evoked neurotransmitter release probability. Pairedpulse ratio was significantly lower in Kcnal ${ }^{\mathrm{V} 408 \mathrm{~A} /}+$ mice $(0.49 \pm 0.06, n=6)$ than in Kcna1 ${ }^{+/+}$mice $(0.77 \pm 0.07, n=7$; $P<0.01$, unpaired $t$-test; Fig. $4 \mathrm{a}, \mathrm{b})$, consistent with an increased release probability. DTx-K had no significant effect on IPSC amplitude in $K c n a 1^{\mathrm{V} 408 \mathrm{~A} /+}$ mice $(4 \pm 5 \%, n=5)$. To examine the downstream consequences for Purkinje cells, we compared their spontaneous activity between Kcnal $\mathrm{V408 \textrm {A } / +}$ and $\mathrm{Kcnal}^{+/+}$ littermates, using cell-attached recordings to minimize disruption of intrinsic excitability. All Purkinje cells irrespective of genotype exhibited periods of tonic firing alternating with periods of quiescence or burst firing (Fig. 4c), as previously reported in wildtype mice and rats $^{35}$. Overall, spike frequency recorded in Kcna1 ${ }^{\mathrm{V} 408 \mathrm{~A} /+}$ mice was significantly lower $(55.4 \pm 10.7 \mathrm{~Hz}$, $n=13)$ compared with Kcna1 ${ }^{+/}+$littermates $(96.3 \pm 12.1 \mathrm{~Hz}$, $n=20, P<0.02$, Mann-Whitney $U$ test). The average inter-spike interval during tonic firing was significantly longer in Kcnal ${ }^{\mathrm{V} 408 \mathrm{~A} /+}$ mice $(20.6 \pm 2.8 \mathrm{~ms}, n=19)$ than in $\mathrm{Kcnal}^{+/+}$ mice $(10.9 \pm 1.3 \mathrm{~ms}, n=20 ; P<0.01$, Mann-Whitney $U$ test; Fig. $4 \mathrm{~d}, \mathrm{e})$. The number of spikes per burst was also lower in mutant mice $(10.9 \pm 3.3, n=5)$ than in wild-type mice $(27.9 \pm 3.0$, $n=11 ; P<0.01$, unpaired $t$-test; Fig. $4 \mathrm{f}$ ). No significant difference was observed in burst duration or the inter-burst interval between the genotypes. There was also no difference in action potential width in Purkinje cells between the genotypes, as estimated by integrating the cell-attached recordings ${ }^{36}$ (Supplementary Fig. 7).

Finally, we asked if enhanced spontaneous GABA release contributed to the lower activity of Purkinje cells. Bath application of blockers of $\mathrm{GABA}_{\mathrm{A}}$ and $\mathrm{GABA}_{\mathrm{B}}$ receptors (100 $\mu$ M PTx and $1 \mu \mathrm{M}$ CGP 52432, respectively) led to a greater decrease in inter-spike interval in Kcnal ${ }^{\mathrm{V} 408 \mathrm{~A} /+}$ mice $(33.7 \pm 4.6 \%, n=10)$ than in $K c n a 1^{+/+}$mice $(17.1 \pm 4.1 \%$, $n=8 ; P<0.05$, unpaired $t$-test; Fig. $4 \mathrm{~g}, \mathrm{~h})$. Indeed, the inter-spike interval in the presence of GABA receptor blockers was not significantly different between wild-type and Kcnal ${ }^{\mathrm{V} 408 \mathrm{~A} /+}$ mice $(11.3 \pm 1.9 \mathrm{~ms}$ and $15.6 \pm 2.1 \mathrm{~ms} ; P=0.36$, unpaired $t$-test $)$. We thus conclude that enhanced GABA release indeed contributes to decreased spontaneous activity of Purkinje cells, with no evidence for a homoeostatic compensation in the EA1 mouse model.

\section{Discussion}

The present study reveals a major role of Kv1.1 channels in action potential repolarization at basket cell terminals, which was not apparent when recording from somata. We provide a quantitative account of presynaptic spike-evoked $\mathrm{Ca}^{2}+$ transients. EA1 modelled in heterozygous knock-in mice led to a similar effect on spike shape and neurotransmitter release, as acute pharmacological blockade of Kv1.1 channels in wild-type mice. GABAergic inhibition of Purkinje cell firing was enhanced in Kcna1 ${ }^{\mathrm{V} 408 \mathrm{~A} /+}$ mice, with no evidence of homoeostatic compensation for this presynaptic channelopathy.

Central to this study is the ability to target small GABAergic presynaptic terminals for whole-cell patch-clamp recordings. This has only previously been achieved in voltage-clamp mode ${ }^{21}$. Presynaptic recordings have yielded invaluable insights into mechanisms linking action potentials and $\mathrm{K}^{+}$channels to neurotransmitter release, but hitherto such studies have been restricted to giant calyceal synapses in the auditory brainstem ${ }^{37}$ or large hippocampal or cerebellar mossy fibre boutons ${ }^{38,39}$. Small boutons can also be targeted for whole-cell patch-clamp using scanning ion conductance microscopy, but this is restricted to cultured neurons ${ }^{40}$. Less invasive methods include boutonattached recordings ${ }^{41}$ and voltage-sensitive dye imaging. A study using both of these methods in cerebellar stellate cells revealed an 
a

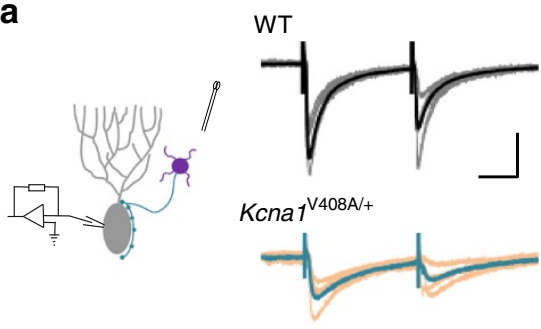

b

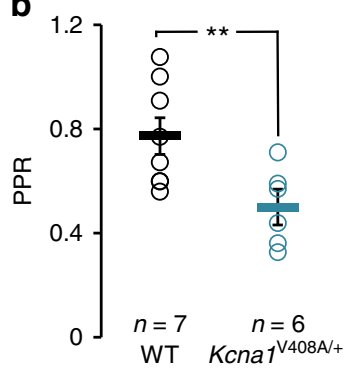

C
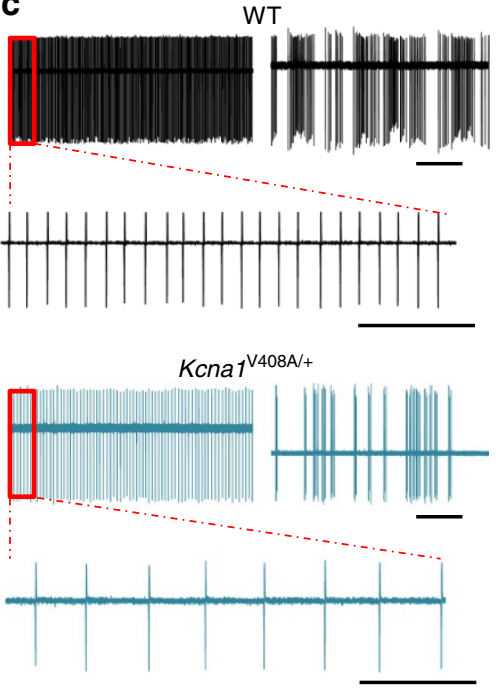

d
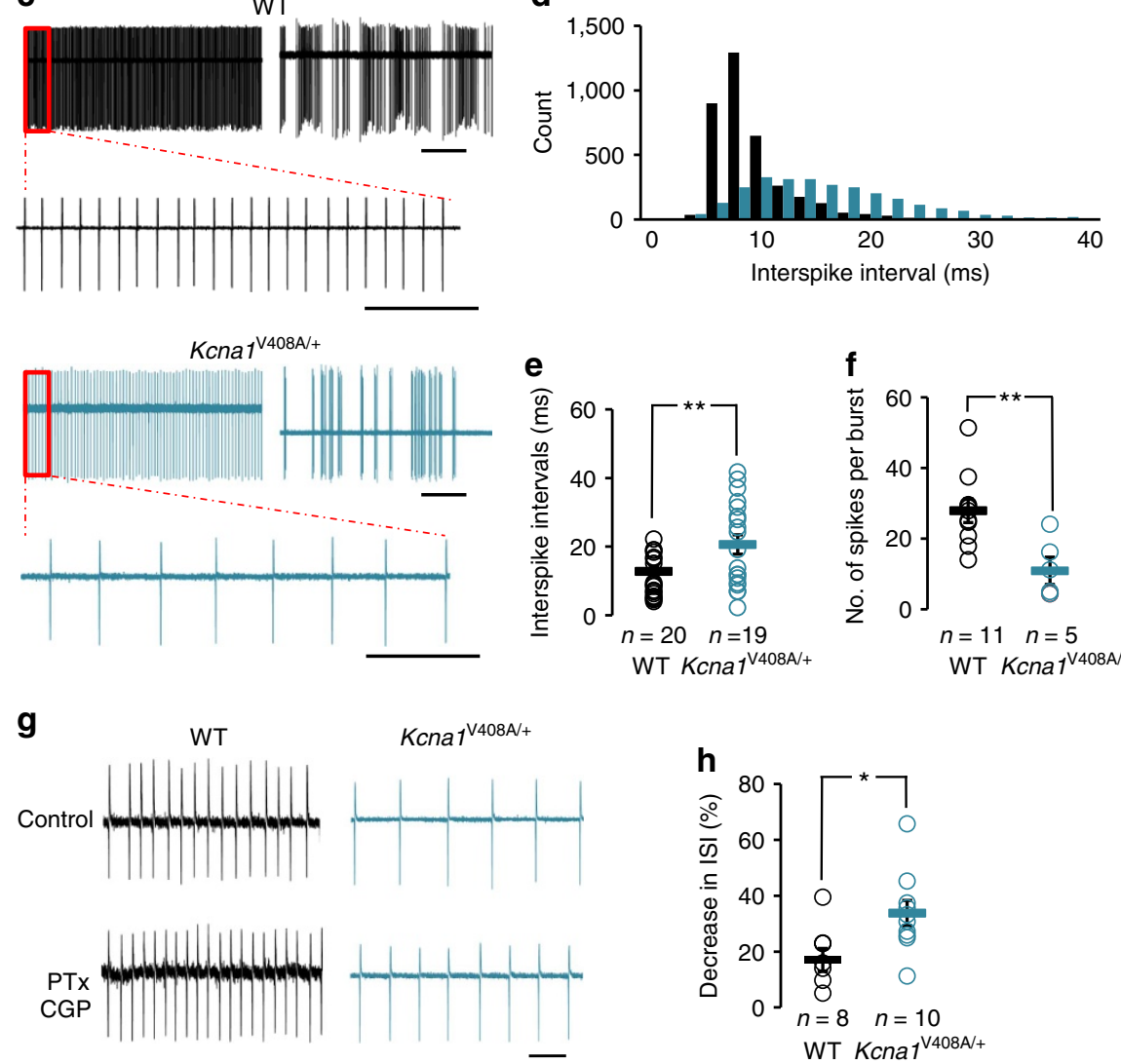

Figure 4 | Increased GABA release at basket cell terminals in Kcna1 $\mathbf{V 4 0 8 A} /+$ mice attenuates spontaneous Purkinje cell firing. (a) IPSCs recorded in cerebellar Purkinje cells of wild-type and $K c n a 1^{\mathrm{V} 408 \mathrm{~A} /+}$ mice. Grey and orange traces: individual sweeps. Black and turquoise traces: averages. Scale bar, 200 pA; 10 ms. (b) PPR was significantly lower in Kcna 1 408A/ + than wild-type Purkinje cells. (c) Representative cell-attached recordings from wild-type and Kcna $7^{\mathrm{V} 408 \mathrm{~A} /+}$ Purkinje cells, illustrating tonic and burst firing, and periods of quiescence. Scale bar, $500 \mathrm{~ms}$; 50 ms (expanded traces). (d) Inter-spike interval distribution during tonic firing (same cells as in c). (e) Average inter-spike interval was significantly longer in Kcna ${ }^{\mathrm{V} 408 \mathrm{~A} /+}+$ than wild-type Purkinje cells. (f) Average number of action potentials per burst was significantly higher in wild-type neurons. ( $\mathbf{g}$ ) Representative traces showing a greater decrease in inter-spike interval following PTx $(100 \mu \mathrm{M})$ and CGP $(1 \mu \mathrm{M})$ perfusion in Kcna1 $\mathrm{V} 408 \mathrm{~A} /+$ than wild-type neurons (Scale bar, 20 ms). (h) Summary of effect of GABA receptor blockade. ${ }^{\star} P<0.05$; ${ }^{\star \star} P<0.01$, unpaired $t$-tests $(\mathbf{b}, \mathbf{f}, \mathbf{h})$ or Mann-Whitney $U$ test $(\mathbf{e})$.

important role of Kv1 channels in action potential shape and activity-dependent broadening at the axon initial segment ${ }^{42}$. However, in striking contrast to the present results, Kv1 family channels were found to play only a minor role in boutons. The difference is consistent with the intense staining for Kv1.1 and $\mathrm{Kv1.2}$, specifically in the terminals of basket cells ${ }^{9-12}$. Several other roles have been inferred for axonal Kv1.1 channels on the basis of somatic recordings. These include delayed spiking in some forebrain interneurons ${ }^{2,19}$ and subthreshold modulation of neurotransmitter release ${ }^{43}$.

The direct recordings from basket cell boutons reported here revealed an increase in spike width by acute application of the Kv1.1-specific blocker DTx-K, which was qualitatively similar to the effect of the Kcnal $1^{\mathrm{V} 408 \mathrm{~A} /+}$ mutation. The Kcnal ${ }^{\mathrm{V} 408 \mathrm{~A} /+}$ mutation, however, had a larger effect than pharmacological blockade (spike width at $-30 \mathrm{mV}$ : $1.26 \pm 0.08 \mathrm{~ms}$ and $1.15 \pm 0.02 \mathrm{~ms}$, respectively), consistent with a dominant negative effect and heteromultimeric assembly of Kv1 channels. Mutant mice also exhibit an increase in spontaneous IPSCs, but no difference in basket cell firing rate or in miniature IPSC amplitude $^{18}$. We failed to observe a compensation for the genetic lesion at the level of spike shape, GABA release or downstream effects on Purkinje cell firing. This is arguably unexpected, given the abundant evidence that blocking neurotransmitter receptors or $\mathrm{Na}^{+}$channels for a few days results in extensive synaptic plasticity, contributing to homoeostatic regulation of neuronal activity ${ }^{24}$. Most attention has hitherto been given to homoeostatic plasticity at 
glutamatergic synapses. However, GABAergic synaptic strength has also been shown to undergo activity-dependent plasticity that compensates for altered activity ${ }^{4-46}$. The results of the present study question the importance of these phenomena for an inherited presynaptic $\mathrm{K}^{+}$channelopathy. A possible explanation is that basket cell synapses are intrinsically less plastic than synapses in the forebrain, although the finding that spontaneous Purkinje cell firing was depressed in $\mathrm{Knal}^{\mathrm{V} 408 \mathrm{~A} /+}$ mice further argues against a major role of homoeostatic plasticity in the cerebellar cortex.

The present study stresses the role of Kv1.1 in ensuring rapid repolarization. It is tempting to speculate that the very high density of Kv1.1 channels in basket cell terminals is an evolutionary adaptation related to the electrotonic properties of a relatively short but profusely arborizing axon, compromising the ability of passive charge dissipation to terminate action potentials. Basket cell terminals also have a prominent ADP that is not affected by either pharmacological or genetic manipulation of Kv1.1, or $\mathrm{GABA}_{\mathrm{A}}$ receptor blockade, and whose biophysical basis remains to be elucidated. Another anatomical peculiarity of basket cell terminals, the 'pinceau' formation, where ephaptic transmission also contributes to inhibition of Purkinje cells ${ }^{47,48}$, only forms at a later developmental stage ${ }^{49}$, and so is unlikely to contribute to spike shape in the present study.

We observed a complementary compartmentalization of $\mathrm{BK}_{\mathrm{Ca}}$ channels, blockade of which affected somatic, but not presynaptic spike width. A pronounced effect of ChTx on somatic $\mathrm{K}^{+}$ currents has not been reported previously. Although $\mathrm{BK}_{\mathrm{Ca}}$ channels are usually abundantly expressed presynaptically, a detailed immunhistochemical study identified cerebellar basket cell synapses as the sole exception to this rule, with greater postthan presynaptic expression ${ }^{29}$. The effect of $\mathrm{BK}_{\mathrm{Ca}}$ channel blockade on somatic action potential width is also unexpected because they generally require a large depolarization and a high local $\mathrm{Ca}^{2+}$ concentration to open ${ }^{50}$. Although $\mathrm{BK}_{\mathrm{Ca}}$ channels are present at cerebellar mossy fibre terminals, their role in action potential repolarization is masked by recruitment of fast $\mathrm{Kv} 3$ channels ${ }^{51}$. We cannot exclude a possible role for presynaptic $\mathrm{BK}_{\mathrm{Ca}}$ channels in basket cells under conditions when other $\mathrm{K}^{+}$ channels are non-functional.

Acute blockade of Kv1.1 channels with DTx-K led to an increase in action potential-evoked $\mathrm{Ca}^{2+}$ influx, which was not observed in a previous study ${ }^{23}$. This is consistent with spike width as a major determinant of $\mathrm{Ca}^{2+}$ channel activation and total $\mathrm{Ca}^{2+}$ influx ${ }^{52}$. Indeed, the simulations suggest that the ADP, by comparison, has little effect on $\mathrm{Ca}^{2+}$ influx. We did not attempt to compare presynaptic $\mathrm{Ca}^{2+}$ influx in wild-type and $K_{c n a 1}{ }^{\mathrm{V} 408 \mathrm{~A} /+}$ mice because of the large variability among boutons. Nevertheless, both pharmacological and genetic manipulations of Kv1.1 led to a marked increase in evoked and spontaneous GABA release, consistent with a supralinear relationship between $\mathrm{Ca}^{2+}$ influx and exocytosis ${ }^{33,34}$. In common with many other neurological channelopathies, the paroxysmal nature of EA1 remains unexplained. Although we have only examined in detail one synapse in the cerebellar circuit, where Kv1.1 is most abundantly expressed, we cannot exclude a role for other elements of the cerebellar circuitry. Strikingly, cerebellar incoordination both in patients with EA1 and in mice harbouring the V408A mutation is triggered by stress, suggesting a role for neuromodulators.

\section{Methods}

Cerebellar slices. Kcna1 ${ }^{\mathrm{V} 408 \mathrm{~A} /+}$ mice were a generous gift from J. Maylie. Breeding pairs were set-up between a heterozygous Kcnal ${ }^{\mathrm{V} 408 \mathrm{~A} /}+$ female and a wild-type C57/BL6 mouse (Harlan), and refreshed after 6 months. This study was performed in accordance with the Animals (Scientific Procedures) Act 1986.
All experiments were performed and analysed blind to genotype. Acute parasagittal cerebellar slices $(300-\mu \mathrm{m}$ thick) were prepared from postnatal day 14-20 mutant and wild-type littermates using a vibrating microtome (Leica VT 1200) in an ice-cold solution containing (in mM): 75 sucrose, $87 \mathrm{NaCl}, 2.5 \mathrm{KCl}, 25$ $\mathrm{NaHCO}_{3}, 1.25 \mathrm{NaH}_{2} \mathrm{PO}_{4}, 7 \mathrm{MgCl}_{2}, 0.5 \mathrm{CaCl}_{2}$ and 20 glucose, $(\mathrm{pH}=7.4$ when gassed with $95 \% \mathrm{O}_{2}: 5 \% \mathrm{CO}_{2}$ ). Slices were warmed to $32^{\circ} \mathrm{C}$ for $10 \mathrm{~min}$ and then stored in a carbogen-gassed solution at room temperature containing (in $\mathrm{mM}$ ): 126 $\mathrm{NaCl}, 2.5 \mathrm{KCl}, 25 \mathrm{NaHCO}_{3}, 1.25 \mathrm{NaH}_{2} \mathrm{PO}_{4}, 1 \mathrm{MgCl}_{2}, 2.0 \mathrm{CaCl}_{2}$ and 10 glucose. The same solution was used to perfuse slices during electrophysiological recordings. Slices were used within $3 \mathrm{~h}$ of preparation.

Electrophysiology. Slices were anchored in a recording chamber mounted on the stage of an upright microscope (BX51WI, Olympus) and visualized with infrared differential interference contrast optics with a $\times 20$ water immersion objective. Slices were continuously perfused at a rate of $3 \mathrm{ml} \mathrm{min}^{-1}$ and recordings were obtained at $33-35^{\circ} \mathrm{C}$. AMPA and NMDA receptors were blocked throughout. Purkinje cells and basket cell somata were patch clamped with 4-6-M $\Omega$ glass pipettes, to achieve an access resistance $<20 \mathrm{M} \Omega$. Bouton recordings were obtained with 9-11-M $\Omega$ glass pipettes, to achieve an access resistance of $<50 \mathrm{M} \Omega$. Basket cell boutons were identified by their size, shape, apposition to Purkinje cell somata and input resistance $\sim 1 \mathrm{G} \Omega$.

For current-clamp experiments the pipette solution contained (in $\mathrm{mM}$ ): 134 K-gluconate; $5 \mathrm{KCl}, 10$ phosphocreatine, $10 \mathrm{HEPES}, 2-5$ EGTA, $0.3 \mathrm{Na}_{3} \mathrm{GTP}$ and 4 MgATP, as well as $2 \mathrm{mg} \mathrm{ml}^{-1}$ biocytin or $200 \mathrm{nM}$ Alexa 568 (adjusted to $\mathrm{pH}$ 7.2-7.3 with $\mathrm{KOH}$ ). If necessary, current was injected to maintain the membrane potential between -70 and $-75 \mathrm{mV}$. Boutons could be made to fire one-to-one in response to 0.5 - or 1-ms current injections delivered at 55 or $100 \mathrm{~Hz}$.

For voltage-clamp experiments, the pipette solution contained (in mM): 140 CsCl; 1 EGTA, 10 HEPES, $1 \mathrm{MgCl}_{2}, 0.3 \mathrm{Na}_{3} \mathrm{GTP}, 5 \mathrm{MgATP}, 1-2 \mathrm{QX} 314-\mathrm{Br}$ and $\mathrm{pH} 7.2-7.3$ with $\mathrm{CsOH}$. Purkinje cell somata were voltage clamped at $-70 \mathrm{mV}$. Whole-cell capacitance and series resistance were compensated. IPSCs were elicited in Purkinje cells using an extracellular stimulating electrode placed in the molecular layer.

To measure the spontaneous firing rates of Purkinje cells, pipettes were filled with the perfusion solution, and voltage-clamp recordings were obtained in the cell-attached mode.

Data were acquired using a Multiclamp 700B amplifier (Molecular Devices) and custom software (National Instruments LabView). Data were low-pass filtered $(20 \mathrm{kHz})$ and digitized at $50 \mathrm{kHz}$.

All data from Kcnal $1^{\mathrm{V} 408 \mathrm{~A} /+}$ mice were compared with data from their wildtype littermates. Data were analysed using LabView and are presented as mean \pm s.e.m. The action potential width was measured at $-30 \mathrm{mV}$. Recordings where action potentials did not overshoot $0 \mathrm{mV}$ were discarded. To calculate the area under the ADP curves the initial $20 \mathrm{~ms}$ were used. In graphs, open circles represent individual experiments, bars illustrate the averages obtained from all experiments. The paired-pulse ratio was calculated as the ratio of the second IPSC to the second IPSC evoked by two extracellular stimuli at $40 \mathrm{~Hz}$. The voltage threshold was estimated from the maximum of the second time derivative of the voltage.

Two-photon excitation fluorescence imaging. Basket cells held in current-clamp whole-cell mode were loaded with both a morphological dye (Alexa 594, 50 or $100 \mu \mathrm{M})$ and the $\mathrm{Ca}^{2+}$ indicator Fluo-4 $(200 \mu \mathrm{M})$, and imaged in two-photon excitation mode at $800 \mathrm{~nm}$ using a femtosecond Ti:sapphire-pulsed laser (MaiTai, Spectra-Physics). Recordings started at least $20 \mathrm{~min}$ after obtaining the whole-cell configuration. We followed the axon and focused on presynaptic boutons in the Purkinje cell layer. Four 1-ms long depolarizing current pulses were injected at $40 \mathrm{~Hz}$ to evoke action potentials, and the Fluo- 4 fluorescence was measured using line scans across the bouton width. Three or four trials were recorded with an inter-trial interval between $30 \mathrm{~s}$ and $1 \mathrm{~min}$, and the saturated fluorescence $\left(F_{\max }\right)$ was measured with a train of 50 action potentials at $100 \mathrm{~Hz}$. The sequence was repeated at least $10 \mathrm{~min}$ after washing in DTx $(200 \mathrm{nM})$. To improve the signal-tonoise ratio, we took the integral of the Fluo-4 fluorescence signal for $200 \mathrm{~ms}$ from the first action potential (Int- $\Delta F)$, as a measure of total action potential-evoked $\mathrm{Ca}^{2+}$ influx $\Delta\left[\mathrm{Ca}^{2+}\right]$.

Presynaptic $\mathbf{C a}^{2}+$ kinetics. The total magnitude of action potential-evoked presynaptic $\mathrm{Ca}^{2+}$ influx $\Delta\left[\mathrm{Ca}^{2+}\right]$ was estimated using a non-stationary singlecompartment model ${ }^{30,53,54}$. We assumed that, in addition to Fluo-4, the presynaptic bouton contained $150 \mu \mathrm{M}$ of total parvalbumin (equivalent to $8 \mu \mathrm{M}$ of free buffer at rest, where $\left[\mathrm{Ca}^{2+}\right]_{\text {rest }}=10 \mathrm{nM}$ and $\left.\left[\mathrm{Mg}^{2+}\right]_{\text {rest }}=0.5 \mathrm{mM}\right)$. The model operated with only two adjustable (free) parameters: $\Delta\left[\mathrm{Ca}^{2+}\right]$ and the $\mathrm{Ca}^{2+}$ removal rate, which have virtually independent effects on the $\mathrm{Ca}^{2+}$ fluorescence signal ${ }^{54}$, and thus were constrained by a direct fitting procedure to match the simulated and experimental fluorescence profiles. Other model parameters were constrained by measuring the maximal Fluo- 4 fluorescence, which was used to estimate $\left[\mathrm{Ca}^{2+}\right]_{\text {rest }}$ and also the total Fluo- 4 concentration at the time of each measurement. This was necessary because the $\mathrm{Ca}^{2+}$ indicator and morphological tracer did not fully reach a steady state during the time course of the 
experiment (that is, between 20 and $50 \mathrm{~min}$ after obtaining the whole-cell configuration; ref. 53). $\mathrm{Ca}^{2+}$ and $\mathrm{Mg}^{2+}$ binding/unbinding rates of parvalbumin were as in ref. 55 , and $\mathrm{Ca}^{2+}$ binding/unbinding rates of Fluo- 4 were as in refs $30,53,54$.

$\mathbf{C a}^{2}+$ current modelling. Action potential-evoked $\mathrm{Ca}^{2+}$ currents through P/Qtype $\mathrm{Ca}^{2}+$ channels were modelled in the NEURON simulation environment ${ }^{56}$, using a six-state $\mathrm{Ca}^{2}+$ channel model developed for hippocampal mossy fibre boutons ${ }^{31}$ as described in detail previously (ref. 30).

Drugs. To block AMPA, NMDA, GABA $A$ and $\mathrm{GABA}_{\mathrm{B}}$ receptors, $5 \mu \mathrm{M} 2,3$ dihydroxy-6-nitro-7-sulfamoyl-benzo[f] quinoxaline-2,3-dione, $50 \mu \mathrm{M}(2 \mathrm{R})$ amino-5-phosphonovaleric acid (APV), $100 \mu \mathrm{M}$ PTx and $1 \mu \mathrm{M}$ CGP 52432, were added to the perfusate. DTx-K $(200 \mathrm{nM})$ was used to block Kv1.1 channels. ChTx $(100 \mu \mathrm{M})$ was used to block BK $\mathrm{Ca}_{\mathrm{Ca}}$ channels. APV was from Ascent (UK). DTx-K was from Alomone lab (UK). All other compounds were purchased from Tocris (Bristol).

Statistics. Data sets that passed the Shapiro-Wilk test for normality were analysed with Student's paired or unpaired $t$-test. Non-parametric tests (Wilcoxon matched pairs signed-rank or Mann-Whitney U) were applied in all other cases.

Data availability. The data that support the findings of this study are available from the corresponding author upon request.

\section{References}

1. Kole, M. H. P., Letzkus, J. J. \& Stuart, G. J. Axon initial segment Kv1 channels control axonal action potential waveform and synaptic efficacy. Neuron 55, 633-647 (2007).

2. Goldberg, E. M. et al. $\mathrm{K}^{+}$channels at the axon initial segment dampen near-threshold excitability of neocortical fast-spiking GABAergic interneurons. Neuron 58, 387-400 (2008).

3. Jan, L. Y. \& Jan, Y. N. Voltage-gated potassium channels and the diversity of electrical signalling. J. Physiol. 590, 2591-2599 (2012).

4. Browne, D. L. et al. Episodic ataxia/myokymia syndrome is associated with point mutations in the human potassium channel gene, KCNA1. Nat. Genet. 8, 136-140 (1994).

5. Browne, D. L. et al. Identification of two new KCNA1 mutations in episodic ataxia/myokymia families. Hum. Mol. Genet 4, 1671-1672 (1995).

6. Zuberi, S. M. et al. A novel mutation in the human voltage-gated potassium channel gene (Kv1.1) associates with episodic ataxia type 1 and sometimes with partial epilepsy. Brain J. Neurol. 122, 817-825 (1999).

7. Eunson, L. H. et al. Clinical, genetic, and expression studies of mutations in the potassium channel gene KCNA1 reveal new phenotypic variability. Ann. Neurol. 48, 647-656 (2000)

8. Rajakulendran, S., Schorge, S., Kullmann, D. M. \& Hanna, M. G. Episodic ataxia type 1: a neuronal potassium channelopathy. Neurotherapeutics 4, 258-266 (2007).

9. Laube, G. et al. Ultrastructural localization of Shaker-related potassium channel subunits and synapse-associated protein 90 to septate-like junctions in rat cerebellar Pinceaux. Brain Res. Mol. Brain Res. 42, 51-61 (1996).

10. Trimmer, J. S. Subcellular localization of $\mathrm{K}^{+}$channels in mammalian brain neurons: remarkable precision in the midst of extraordinary complexity. Neuron 85, 238-256 (2015)

11. Wang, H., Kunkel, D. D., Martin, T. M., Schwartzkroin, P. A. \& Tempel, B. L. Heteromultimeric $\mathrm{K}^{+}$channels in terminal and juxtaparanodal regions of neurons. Nature 365, 75-79 (1993).

12. Wang, H., Kunkel, D. D., Schwartzkroin, P. A. \& Tempel, B. L. Localization of Kv1.1 and Kv1.2, two K channel proteins, to synaptic terminals, somata, and dendrites in the mouse brain. J. Neurosci. 14, 4588-4599 (1994).

13. Adelman, J. P., Bond, C. T., Pessia, M. \& Maylie, J. Episodic ataxia results from voltage-dependent potassium channels with altered functions. Neuron 15, 1449-1454 (1995).

14. D’Adamo, M. C., Liu, Z., Adelman, J. P., Maylie, J. \& Pessia, M. Episodic ataxia type-1 mutations in the hKv1.1 cytoplasmic pore region alter the gating properties of the channel. EMBO J. 17, 1200-1207 (1998).

15. Rea, R., Spauschus, A., Eunson, L. H., Hanna, M. G. \& Kullmann, D. M. Variable $\mathrm{K}^{(+)}$channel subunit dysfunction in inherited mutations of KCNA1. J. Physiol. 538, 5-23 (2002).

16. Maylie, B., Bissonnette, E., Virk, M., Adelman, J. P. \& Maylie, J. G. Episodic ataxia type 1 mutations in the human Kv1.1 potassium channel alter hKvbeta 1-induced N-type inactivation. J. Neurosci. 22, 4786-4793 (2002).

17. Imbrici, P., D’Adamo, M. C., Kullmann, D. M. \& Pessia, M. Episodic ataxia type 1 mutations in the KCNA1 gene impair the fast inactivation properties of the human potassium channels Kv1.4-1.1/Kvbeta1.1 and Kv1.4-1.1/Kvbeta1.2. Eur. J. Neurosci. 24, 3073-3083 (2006).
18. Herson, P. S. et al. A mouse model of episodic ataxia type-1. Nat. Neurosci. 6 , 378-383 (2003).

19. Dehorter, N. et al. Tuning of fast-spiking interneuron properties by an activity-dependent transcriptional switch. Science 349, 1216-1220 (2015).

20. Harvey, A. L. \& Robertson, B. Dendrotoxins: Structure-Activity Relationships and Effects on Potassium Ion Channels. Curr. Med. Chem. 11, 3065-3072 (2004).

21. Southan, A. P. \& Robertson, B. Electrophysiological characterization of voltagegated $\mathrm{K}^{(+)}$currents in cerebellar basket and purkinje cells: Kv1 and Kv3 channel subfamilies are present in basket cell nerve terminals. J. Neurosci. 20, 114-122 (2000).

22. Southan, A. P. \& Robertson, B. Modulation of inhibitory post-synaptic currents (IPSCs) in mouse cerebellar Purkinje and basket cells by snake and scorpion toxin $\mathrm{K}^{+}$channel blockers. Br. J. Pharmacol. 125, 1375-1381 (1998).

23. Tan, Y. P. \& Llano, I. Modulation by $\mathrm{K}^{+}$channels of action potential-evoked intracellular $\mathrm{Ca}^{2}+$ concentration rises in rat cerebellar basket cell axons. J. Physiol. 520(Pt 1): 65-78 (1999).

24. Turrigiano, G. Too many cooks? Intrinsic and synaptic homeostatic mechanisms in cortical circuit refinement. Annu. Rev. Neurosci. 34, 89-103 (2011).

25. Robertson, B., Owen, D., Stow, J., Butler, C. \& Newland, C. Novel effects of dendrotoxin homologues on subtypes of mammalian Kv1 potassium channels expressed in Xenopus oocytes. FEBS Lett. 383, 26-30 (1996).

26. Southan, A. P. \& Robertson, B. Patch-clamp recordings from cerebellar basket cell bodies and their presynaptic terminals reveal an asymmetric distribution of voltage-gated potassium channels. J. Neurosci. 18, 948-955 (1998).

27. Trigo, F. F., Chat, M. \& Marty, A. Enhancement of GABA release through endogenous activation of axonal GABA(A) receptors in juvenile cerebellum. J. Neurosci. 27, 12452-12463 (2007).

28. $\mathrm{Hu}, \mathrm{H}$. et al. Presynaptic $\mathrm{Ca}^{2+}$-activated $\mathrm{K}^{+}$channels in glutamatergic hippocampal terminals and their role in spike repolarization and regulation of transmitter release. J. Neurosci. 21, 9585-9597 (2001).

29. Knaus, H. G. et al. Distribution of high-conductance $\mathrm{Ca}^{(2+)}$-activated $\mathrm{K}^{+}$channels in rat brain: targeting to axons and nerve terminals. J. Neurosci. 16, 955-963 (1996).

30. Ermolyuk, Y. S. et al. Differential triggering of spontaneous glutamate release by P/Q-, N- and R-type $\mathrm{Ca}^{2+}$ channels. Nat. Neurosci. 16, 1754-1763 (2013).

31. Li, L., Bischofberger, J. \& Jonas, P. Differential gating and recruitment of P/Q$\mathrm{N}$-, and R-type $\mathrm{Ca}^{2+}$ channels in hippocampal mossy fiber boutons. J. Neurosci. 27, 13420-13429 (2007).

32. Stephens, G. J., Morris, N. P., Fyffe, R. E. W. \& Robertson, B. The Cav2.1/ $\alpha 1$ A (P/Q-type) voltage-dependent calcium channel mediates inhibitory neurotransmission onto mouse cerebellar Purkinje cells. Eur. J. Neurosci. 13, 1902-1912 (2001).

33. Matveev, V., Bertram, R. \& Sherman, A. $\mathrm{Ca}^{2}+$ current versus $\mathrm{Ca}^{2}+$ channel cooperativity of exocytosis. J. Neurosci. 29, 12196-12209 (2009).

34. Bucurenciu, I., Kulik, A., Schwaller, B., Frotscher, M. \& Jonas, P. Nanodomain coupling between $\mathrm{Ca}^{2}+$ channels and $\mathrm{Ca}^{2}+$ sensors promotes fast and efficient transmitter release at a cortical GABAergic synapse. Neuron 57, 536-545 (2008).

35. Womack, M. D. \& Khodakhah, K. Dendritic control of spontaneous bursting in cerebellar Purkinje cells. J. Neurosci. 24, 3511-3521 (2004).

36. Sasaki, T., Matsuki, N. \& Ikegaya, Y. Targeted axon-attached recording with fluorescent patch-clamp pipettes in brain slices. Nat. Protoc. 7, 1228-1234 (2012).

37. Nakamura, Y. \& Takahashi, T. Developmental changes in potassium currents at the rat calyx of Held presynaptic terminal. J. Physiol. 581, 1101-1112 (2007).

38. Bischofberger, J., Engel, D., Li, L., Geiger, J. R. P. \& Jonas, P. Patch-clamp recording from mossy fiber terminals in hippocampal slices. Nat. Protoc. 1, 2075-2081 (2006).

39. Rancz, E. A. et al. High-fidelity transmission of sensory information by single cerebellar mossy fibre boutons. Nature 450, 1245-1248 (2007).

40. Novak, P. et al. Nanoscale-targeted patch-clamp recordings of functional presynaptic ion channels. Neuron 79, 1067-1077 (2013).

41. Kawaguchi, S. \& Sakaba, T. Control of inhibitory synaptic outputs by low excitability of axon terminals revealed by direct recording. Neuron $\mathbf{8 5}$, 1273-1288 (2015).

42. Rowan, M. J. M., Tranquil, E. \& Christie, J. M. Distinct Kv channel subtypes contribute to differences in spike signaling properties in the axon initial segment and presynaptic boutons of cerebellar interneurons. J. Neurosci. 34, 6611-6623 (2014).

43. Bialowas, A. et al. Analog modulation of spike-evoked transmission in CA3 circuits is determined by axonal Kv1.1 channels in a time-dependent manner. Eur. J. Neurosci. 41, 293-304 (2015).

44. Xu, C., Zhao, M., Poo, M. \& Zhang, X. GABA(B) receptor activation mediates frequency-dependent plasticity of developing GABAergic synapses. Nat. Neurosci. 11, 1410-1418 (2008). 
45. Maffei, A., Nataraj, K., Nelson, S. B. \& Turrigiano, G. G. Potentiation of cortical inhibition by visual deprivation. Nature 443, 81-84 (2006).

46. Nahmani, M. \& Turrigiano, G. G. Deprivation-induced strengthening of presynaptic and postsynaptic inhibitory transmission in layer 4 of visual cortex during the critical period. J. Neurosci. 34, 2571-2582 (2014).

47. Blot, A. \& Barbour, B. Ultra-rapid axon-axon ephaptic inhibition of cerebellar Purkinje cells by the pinceau. Nat. Neurosci. 17, 289-295 (2014).

48. Kole, M. J. et al. Selective loss of presynaptic potassium channel clusters at the cerebellar basket cell terminal pinceau in adam 11 mutants reveals their role in ephaptic control of purkinje cell firing. J. Neurosci. 35, 11433-11444 (2015).

49. Sotelo, C. Development of 'Pinceaux' formations and dendritic translocation of climbing fibers during the acquisition of the balance between glutamatergic and gamma-aminobutyric acidergic inputs in developing Purkinje cells. J. Comp. Neurol. 506, 240-262 (2008).

50. Fakler, B. \& Adelman, J. P. Control of $\mathrm{K}(\mathrm{Ca})$ channels by calcium nano/ microdomains. Neuron 59, 873-881 (2008).

51. Alle, H., Kubota, H. \& Geiger, J. R. P. Sparse but highly efficient Kv3 outpace BKCa channels in action potential repolarization at hippocampal mossy fiber boutons. J. Neurosci. 31, 8001-8012 (2011).

52. Bischofberger, J., Geiger, J. R. P. \& Jonas, P. Timing and efficacy of $\mathrm{Ca}^{2+}$ channel activation in hippocampal mossy fiber boutons. J. Neurosci. 22, 10593-10602 (2002).

53. Ermolyuk, Y. S. et al. Independent regulation of basal neurotransmitter release efficacy by variable $\mathrm{Ca}^{2}+$ influx and bouton size at small central synapses. PLoS Biol. 10, e1001396 (2012).

54. Scott, R. \& Rusakov, D. A. Main determinants of presynaptic $\mathrm{Ca}^{2+}$ dynamics at individual mossy fiber-CA3 pyramidal cell synapses. J. Neurosci. 26, 7071-7081 (2006)

55. Eggermann, E. \& Jonas, P. How the 'slow' $\mathrm{Ca}^{(2+)}$ buffer parvalbumin affects transmitter release in nanodomain-coupling regimes. Nat. Neurosci. 15, 20-22 (2012).

56. Hines, M. L. \& Carnevale, N. T. The NEURON simulation environment. Neural Comput. 9, 1179-1209 (1997).

\section{Acknowledgements}

We are indebted to J. Maylie for the gift of the Kcnal ${ }^{\mathrm{V} 408 \mathrm{~A} /+}$ mice, to M. Cano and S. Martin for the help with breeding and genotyping, to Y. Timofeeva for the help with simulations, to D.A. Rusakov for the help with $\mathrm{Ca}^{2}+$ imaging and to S. Schorge, M.C. Walker, D. Attwell and R.A. Silver for helpful comments. This work was supported by the Medical Research Council, European Research Council and Wellcome Trust.

\section{Author contributions}

R.B. performed the electrophysiological experiments. Y.B. performed the $\mathrm{Ca}^{2}+$ imaging experiments. K.E.V. analysed the $\mathrm{Ca}^{2}+$ fluorescence data and modelled presynaptic $\mathrm{Ca}^{2}+$ kinetics. D.M.K. designed the project. D.M.K. and R.B. wrote the manuscript with revisions from co-authors. The authors declare no competing financial interests.

\section{Additional information}

Supplementary Information accompanies this paper at http://www.nature.com/ naturecommunications

Competing financial interests: The authors declare no competing financial interests.

Reprints and permission information is available online at http://npg.nature.com/ reprintsandpermissions/

How to cite this article: Begum, R. et al. Action potential broadening in a presynaptic channelopathy. Nat. Commun. 7:12102 doi: 10.1038/ncomms12102 (2016).

(c) (i) This work is licensed under a Creative Commons Attribution 4.0 International License. The images or other third party material in this article are included in the article's Creative Commons license, unless indicated otherwise in the credit line; if the material is not included under the Creative Commons license, users will need to obtain permission from the license holder to reproduce the material. To view a copy of this license, visit http://creativecommons.org/licenses/by/4.0/

(C) The Author(s) 2016 